\title{
BMJ Open Prevalence of osteoporosis among North Korean women refugees living in South Korea: a comparative cross- sectional study
}

\author{
Kyeong Jin Kim, ${ }^{1}$ Jee Hyun An, ${ }^{1}$ Kyoung Jin Kim, ${ }^{1}$ Ji Hee Yu, ${ }^{1}$ Nam Hoon Kim, ${ }^{1}$ \\ Hye Jin Yoo, ${ }^{1}$ Hee Young Kim, ${ }^{1}$ Ji A Seo, ${ }^{1}$ Nan Hee Kim, ${ }^{1}$ Kyung Mook Choi (D) , \\ Sei Hyun Baik, ${ }^{1}$ Sin Gon Kim (1) ${ }^{1,2}$
}

To cite: Kim KJ, An JH, Kim KJ, et al. Prevalence of osteoporosis among North Korean women refugees living in South Korea: a comparative cross-sectional study. BMJ Open 2020;10:e036230. doi:10.1136/ bmjopen-2019-036230

- Prepublication history for this paper is available online. To view these files, please visit the journal online (http://dx.doi. org/10.1136/bmjopen-2019036230).

Received 06 December 2019 Revised 16 February 2020 Accepted 05 May 2020
Check for updates

(C) Author(s) (or their employer(s)) 2020. Re-use permitted under CC BY-NC. No commercial re-use. See rights and permissions. Published by BMJ.

${ }^{1}$ Department of Internal Medicine, Korea University College of Medicine, Seoul, The Republic of Korea

${ }^{2}$ Department of Healthcare and Medicine for Unified Korea,

Korea University College of Medicine, Seoul, The Republic of Korea

Correspondence to

Dr Sin Gon Kim;

k50367@korea.ac.kr

\section{ABSTRACT}

Objective To investigate the prevalence of osteoporosis among North Korean women refugees when compared with South Korean women, who have identical genetic backgrounds but experience different environments.

Design Comparative cross-sectional study.

Setting North Korean Refugee Health in South Korea (NORNS) study in South Korea.

Participants We evaluated 122 North Korean women who participated in NORNS study and 366 age-matched/ menopausal status-matched South Korean women from the Korea University Medical Center (KUMC) health examination cohort. The median age of the NORNS participants was 46 years (IQR, 40-60 years) with 52 women (42.6\%) being postmenopausal.

Results Among the postmenopausal women, NORNS participants had a higher body mass index and number of pregnancies and lower physical activity than the KUMC participants. The overall prevalence of osteoporosis was $48 \%(25 / 52)$ and $17 \%(27 / 156)$ in NORNS and KUMC participants, respectively. The bone mineral density (BMD) values at the lumbar spine, femur neck and total hip were significantly lower in postmenopausal NORNS women than in the postmenopausal KUMC women. Old age, low body weight and late age of menarche were associated with low BMD among the postmenopausal North Korean refugees. In premenopausal participants, the NORNS women had lower body weight and physical activity than the KUMC women at baseline. All the NORNS women had normal Z-scores, although the BMD at the lumbar spine was significantly lower in NORNS women than in the KUMC women $\left(0.952\right.$ vs $\left.1.002 \mathrm{~g} / \mathrm{cm}^{2}, \mathrm{p}<0.001\right)$.

Conclusions Osteoporosis is a prevalent health problem in postmenopausal North Korean women refugees living in South Korea. It is conceivable to prepare vigilant countermeasures for bone health deterioration in this growing population, especially for postmenopausal women. Further research is warranted to determine the cause of the differences between participants of the same ethnic group.

\section{INTRODUCTION}

Osteoporosis is one of the most common health problems in an aged society,
Strengths and limitations of this study

- We compared the prevalence of osteoporosis between North Korean women refugees and agematched/menopausal status-matched South Korean women of same ethnicity but with different environmental factors.

- This is the first qualitative study using dual-energy X-ray absorptiometry to identify the bone health status of North Korea women refugees living in South Korea.

- All the confounding factors associated with osteoporosis were not included in this study.

- Our analysis, restricted to relatively small portion of North Korean women refugees, minimise the representativeness of the entire North Korean women population.

particularly among older women, leading to fractures that are closely associated with morbidity and mortality. ${ }^{1-3}$ Early detection and risk management can reduce the osteoporosis incidence and prevent fractures. Environmental factors, such as malnutrition, current smoking status, alcohol consumption, physical inactivity and medications such as corticosteroids in addition to inherent factors like older age and female sex, are well-known risk factors for osteoporosis. $^{4-7}$ Moreover, recent epidemiological studies have demonstrated that Asian women immigrants have a high prevalence of osteoporosis and low bone mineral density (BMD). In a study of 73 premenopausal Chinese immigrant women living in Denmark, their BMD was significantly lower than that of the general population of premenopausal Danish women. ${ }^{8}$ Similarly, Marquez et al reported that immigrants from Southeast Asia had a lower BMD than that of white residents living in Minnesota, 
USA. ${ }^{9}$ However, previous studies were not sufficient to distinguish whether the lower BMD between the two groups was due to the environmental factors, including immigration itself, or ethnicities. In this context, how the environmental factors influence the bone health in an immigration population of the same ethnicity has not been clearly elucidated.

The Korean peninsula has been the only divided country in the world since 1945. In the subsequent decades, South and North Korea have experienced stark differences in politics, economics and culture. North Korea has experienced severe poverty due to its economic deterioration and global sanctions ${ }^{10}$; therefore, most North Korean refugees who left North Korea and resettled in South Korea have experienced penury and malnutrition. ${ }^{11} 12$ Moreover, we previously reported a high prevalence of vitamin D deficiency in North Korean refugees that has been well documented for its role in the maintenance of bone health. ${ }^{1314}$

In the present study, we evaluated the prevalence of osteoporosis in North Korean women refugees compared with that in South Korean women, who are of the same ethnicity but who have encountered completely different socioeconomic environments. Furthermore, we analysed the associated risk factors for osteoporosis in North Korean women refugees.

\section{METHODS}

\section{Participants and study design}

The North Korean Refugee Health in South Korea (NORNS) study, which started in October 2008 and is still ongoing, aimed to evaluate the medical health and disease status of North Korean refugees in South Korea. The NORNS study is a longitudinal study consisting of two parts, the first and the second surveys, which followed the same participants as the first survey approximately 3.5 years later. The NORNS study included interviews, structural surveys, physical examinations and blood samples in both the first and second surveys, however, dual-energy X-ray absorptiometry (DXA) was only performed in the second survey. The entire study process was conducted in Anam Hospital at the Korea University Medical Center (KUMC) in Seoul. More specific details on the NORNS study design and general features have been published elsewhere. ${ }^{1315}$

Figure 1 illustrates the study design. Age-matched and menopausal status-matched control subjects were randomly selected at a 1:3 ratio of cases to controls from the KUMC Anam Hospital Health Examination cohort to compare the prevalence of osteoporosis between North Korean women refugees (NORNS group) and South Korean women (KUMC group). Written informed consent was obtained from all participants. We used the Strengthening the Reporting of Observational Studies in Epidemiology reporting guidelines. ${ }^{16}$

\section{Questionnaire and anthropometric measurements}

General demographic data including age, sex, year of emigration from North Korea, year of entry into South Korea, menarche age and menopausal status as well as health-related lifestyle behaviours including smoking, alcohol consumption and physical activity were included in the questionnaire. Anthropometric measurements including height and body weight were conducted after an overnight fast. All the demographic and anthropometric measurements based on the results of the second survey were analysed in this study. For handling the missing data of questionnaire and anthropometric measurements, available-case analyses (also known as pairwise deletion) were used without additional data handing.

\section{BMD measurements}

BMD at the lumbar spine, left femur neck and total hip was measured in the NORNS and KUMC cohorts by DXA using the Hologic Discovery system (HOLOGIC, Waltham, Massachusetts, USA). BMD was expressed as the total bone mineral content $(\mathrm{g})$ divided by the area $\left(\mathrm{cm}^{2}\right)$. The lumbar spine BMD, T-score and Z-score were calculated as the mean values of the L1 through L4 spine. For premenopausal women, a race-adjusted Z-score $\leq-2.0$ was considered to be below the expected range for their age group and a Z-score $>-2.0$ as within the expected range for their age group. For postmenopausal women, osteoporosis was defined as a T-score $\leq-2.5$ in at least one of the lumbar spine, left femur neck, and total hip; osteopenia as a T-score $>-2.5$ and $<-1.0$; normal as a T-score $\geq-1.0 .^{17}$

\section{Statistical analysis}

We presented continuous data as mean and SD using the paired t-test for normally distributed variables and as medians and IQRs using Wilcoxon-Mann-Whitney tests for non-normally distributed variables. Categorical data are presented as frequencies and percentages and were analysed using $\mathrm{X}^{2}$ or Fisher's exact tests for small case

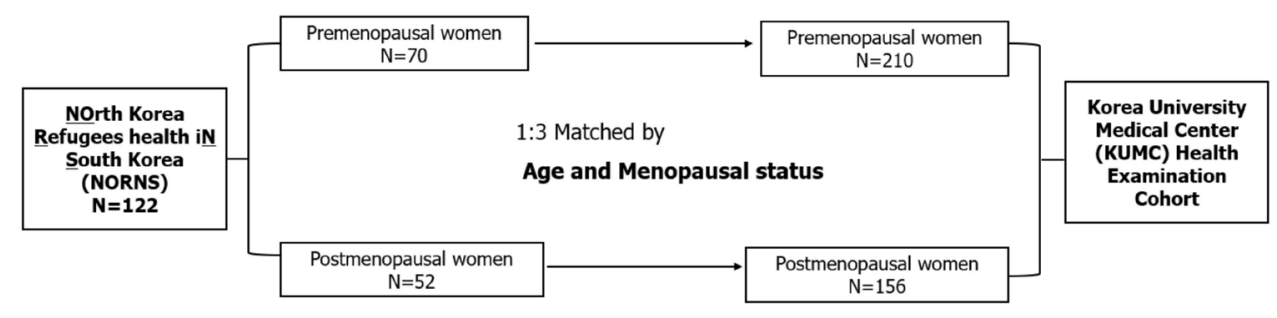

Figure 1 Study design. 
numbers. BMD values between the NORNS and KUMC cohorts were compared using Wilcoxon signed-rank tests. Correlations between BMD and demographic, gynaecological and medical factors in the NORNS cohort were evaluated using a simple linear regression model. Finally, logistic regression analyses were used to investigate the risk factors for osteoporosis in postmenopausal women in the NORNS cohort. All reported p values were two sided and those $<0.05$ were considered statistically significant. All analyses were performed using IBM SPSS Statistics for Windows, V.20.0 (IBM) and GraphPad Prism V.7 (GraphPad Software, San Diego, California, USA).

\section{Patient and public involvement}

Participants of this study or members of the public were not directly and personally involved with study design, data provision, analysis and publication of the study.

\section{RESULTS}

Baseline characteristics of the NORNS and KUMC groups

Among the 122 North Korean refugees, 70 were premenopausal women $(57.4 \%)$ with a median age of 41.0 (IQR $37.0-44.0)$ years and 52 were postmenopausal women $(42.6 \%)$ with a median age of 62.5 (IQR 55.0-68.5) years. The median duration of living in South Korea was 6.2 (IQR 4.2-9.0) years. Their baseline characteristics in comparison with that of KUMC participants according to menopause status are described in table 1 . The NORNS premenopausal women had a significantly lower mean height $(155.0 \pm 4.4$ vs $161.0 \pm 5.2 \mathrm{~cm}, \mathrm{p}<0.001)$ and body weight $(53.2 \pm 6.7$ vs $58.0 \pm 9.4 \mathrm{~kg}, \mathrm{p}<0.001)$ than the KUMC premenopausal women, whereas no difference in body mass index (BMI) $\left(22.1 \pm 2.3\right.$ vs $\left.22.4 \pm 3.4 \mathrm{~kg} / \mathrm{m}^{2}, \mathrm{p}=0.514\right)$ was observed between the two groups. However, the NORNS postmenopausal women had a lower height $(153.1 \pm 4.8$ vs $155.8 \pm 5.3 \mathrm{~cm}, \mathrm{p}=0.002)$ and higher BMI $\left(24.9 \pm 3.2\right.$ vs $\left.23.4 \pm 2.8 \mathrm{~kg} / \mathrm{m}^{2}, \mathrm{p}=0.002\right)$ than the KUMC postmenopausal women. There was no difference in body weight ( $57.8 \pm 7.5$ vs $56.7 \pm 6.8 \mathrm{~kg}, \mathrm{p}=0.320)$ between the two groups. The proportion of subjects engaged in physical activity for more than 5 hours per week was lower in both the NORNS premenopausal and postmenopausal women than in the KUMC premenopausal and postmenopausal women. All NORNS premenopausal women were never smokers, whereas 22 of 210 KUMC premenopausal women were ex-smokers/current smokers $(p=0.006)$.

\section{Comparison of BMD and osteoporosis prevalence between the NORNS and KUMC groups}

Table 2 shows the comparisons of BMD between the NORNS and KUMC groups. In premenopausal women, the lumbar spine BMD of the NORNS group was $0.952 \pm 0.10$, whereas that of the KUMC group was $1.001 \pm 0.12$, a significant difference $(p<0.001)$. Femur neck and total hip BMD did not differ significantly between the two groups. However, in postmenopausal women, the BMD of the lumbar spine, femur neck, and total hip was consistently lower in the NORNS group than in the KUMC group.

All premenopausal participants in the NORNS group had normal Z-scores, whereas four premenopausal women in the KUMC group (1.9\%, 4 of 210) had Z-scores below the expected range for their age group $(p=0.575)$. However, the prevalence of osteoporosis was significantly higher in the postmenopausal NORNS group than that in the postmenopausal KUMC group ( $48.1 \%$ vs $17.3 \%)$ (table 3). The proportion of participants with a normal T-score was more than two times higher in the KUMC postmenopausal group $(20.5 \%, 32$ of 156$)$ than that in the NORNS postmenopausal group $(9.6 \%, 5$ of 52). Figure 2 demonstrates the proportion of participants with osteoporosis and osteopenia in the postmenopausal NORNS and KUMC groups, stratified by 10-year age categories. The prevalence of osteoporosis in the postmenopausal NORNS group was $35 \%$ (7 of 20), 52\% (10 of 19) and $67 \%$ (8 of 12) in participants aged 50-59, 60-69 and $>70$ years, respectively. For postmenopausal KUMC women, the prevalence of osteoporosis in each age group was lower than that of the respective NORNS group $(5 \%, 3$ of $60 ; 26 \%, 15$ of 57 ; and $25 \%, 9$ of 36 in those aged $50-59$, $60-69$ and $>70$ years, respectively). None of the participants over 60 years in the NORNS group had a normal T-score.

\section{Risk factors associated with osteoporosis and low BMD in postmenopausal North Korean refugees}

The risk factors associated with osteoporosis in the NORNS postmenopausal group, identified using multivariate logistic regression analysis, are shown in table 4 . Lower body weight was the only significant risk factor of osteoporosis in this group. Older age and late menarche tend towards osteoporosis but no statistical significance, and duration of living in South Korea was not a risk factor of osteoporosis in this group. In addition, simple linear regression to determine the factors correlated with lumbar spine BMD in the postmenopausal NORNS group revealed that old age, low body weight and late menarche age were significantly associated with low BMD (figure 3). There was no association between the duration of living in South Korea and BMD.

\section{DISCUSSION}

This comparative cross-sectional study demonstrated that the prevalence of osteoporosis in postmenopausal North Korean refugees was significantly higher than that in agematched postmenopausal South Korean women of the general population. BMD values at the lumbar spine, femur neck and total hip were significantly lower in postmenopausal North Korean refugees than those in South Korean postmenopausal women. Low body weight was associated with osteoporosis and low BMD in the NORNS postmenopausal group.

Most of the postmenopausal women (92\%, 48 of 52) in the NORNS group had endured the worst food shortage, 


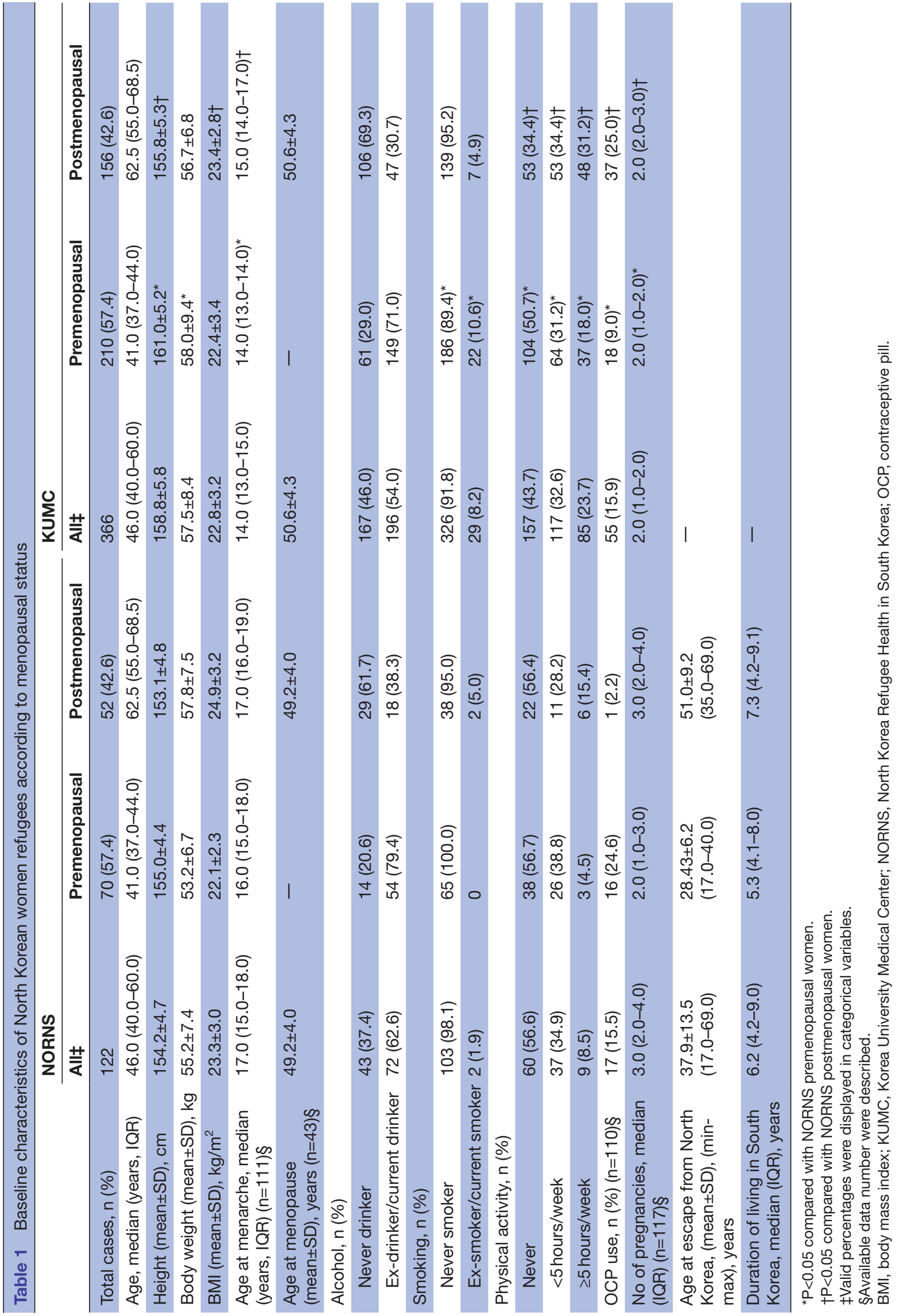

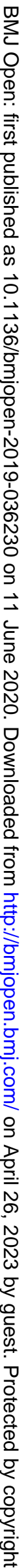


Table 2 Comparisons of BMD at the lumbar spine, femur neck and total hip between North Korean refugee women and South Korean women

\begin{tabular}{rllllll} 
& $\begin{array}{l}\text { Lumbar spine BMD } \\
\left(\mathbf{g} / \mathbf{c m}^{2}\right)\end{array}$ & P value & $\begin{array}{l}\text { Femur neck BMD } \\
\left(\mathbf{g} / \mathbf{c m}^{2}\right)\end{array}$ & $\begin{array}{l}\text { Total hip BMD } \\
\text { P value }\end{array}$ & $\begin{array}{l}\text { (g/cm }) \\
\text { Premenopausal }\end{array}$ \\
& & & & & & \\
NORNS $(\mathrm{n}=70)$ & $0.952 \pm 0.10$ & $<0.001$ & $0.735 \pm 0.08$ & 0.477 & $0.881 \pm 0.13$ & 0.737 \\
KUMC $(\mathrm{n}=210)$ & $1.001 \pm 0.12$ & & $0.741 \pm 0.10$ & & $0.884 \pm 0.10$ & \\
Postmenopausal & & & & & & \\
NORNS ( $\mathrm{n}=52)$ & $0.760 \pm 0.11$ & $<0.001$ & $0.610 \pm 0.10$ & $<0.001$ & $0.774 \pm 0.11$ & 0.002 \\
KUMC $(\mathrm{n}=156)$ & $0.861 \pm 0.12$ & & $0.653 \pm 0.09$ & & $0.808 \pm 0.10$ & \\
\hline
\end{tabular}

Data are expressed as mean \pm SD.

BMD, Bone Mineral Density; KUMC, Korea University Medical Centre; NORNS, North Korea Refugee Health in South Korea.

the Arduous March, between 1996 and 2000 and in which more than 600000 people in North Korea died of starvation. ${ }^{18}$ During this period, they could not obtain sufficient nutrients, including protein, calcium and vitamin $\mathrm{D}$, which have important roles in bone mineral acquisition. Although the actual nutritional status immediately after entering South Korea could not be evaluated due to restricted access authority, the youngest age at the time of escape from North Korea in the postmenopausal NORNS women was 35 years. This means that all postmenopausal participants had experienced malnutrition during their childhood and early adulthood and reached their peak bone mass before leaving North Korea. We consider that this is one of the major reasons why postmenopausal women were more vulnerable to osteoporosis. Several studies have revealed that subjects who experience malnutrition during childhood and early adulthood are less likely to reach peak bone mass, leading to osteoporosis in later life. ${ }^{19-21}$ Our results are also in

Table 3 Prevalence of osteoporosis in North Korean women refugees and South Korean women

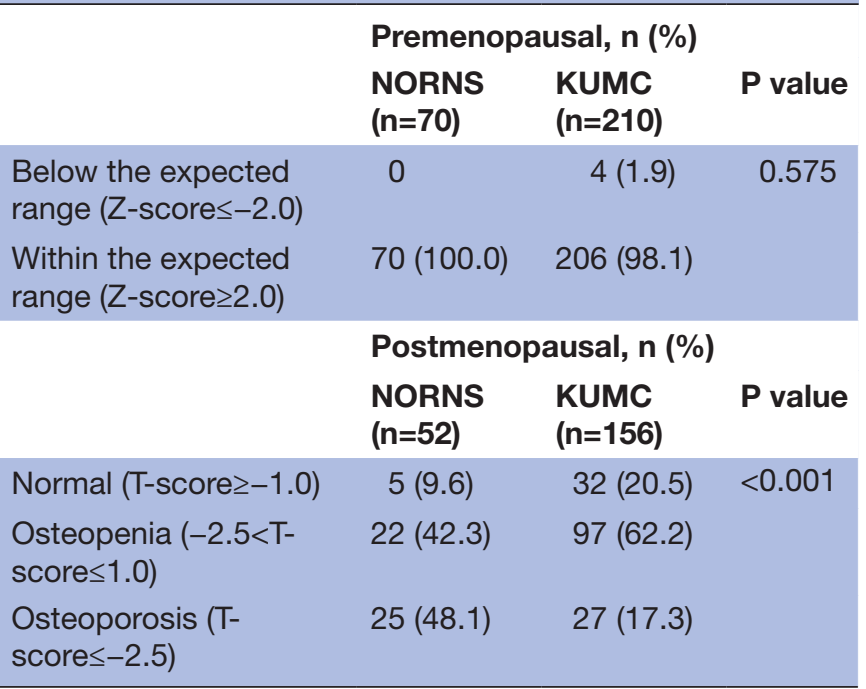

KUMC, Korea University Medical Center; NORNS, North Korea

Refugee Health in South Korea. line with previous cohort studies demonstrating the negative effects of malnutrition and famine on bone health. Marcus et al reported a high prevalence of osteoporosis and osteopenia (55\% and 40\%, respectively) among Holocaust survivors who had experienced malnutrition during their childhood. ${ }^{22}$ Another study conducted in Hong Kong observed that past exposure to famine, especially in childhood, was associated with osteoporosis in postmenopausal women aged 65 years or older. ${ }^{23}$

Vitamin D has been well documented to play an important role in bone mineral metabolism via interactions with calcium and parathyroid hormone. ${ }^{14}$ Our previous study with 366 North Korean refugees demonstrated that the prevalence of vitamin $\mathrm{D}$ deficiency $(25(\mathrm{OH}) \mathrm{D}<20 \mathrm{ng} / \mathrm{mL})$ was $87 \% .{ }^{13}$ In the present study, serum vitamin D levels were only obtained in 66 of 122 NORNS participants (mean level of $15.0 \pm 4.3 \mathrm{ng} / \mathrm{mL}$ ) and no subject had adequate vitamin D level $(25(\mathrm{OH})$ $\mathrm{D} \geq 30 \mathrm{ng} / \mathrm{mL}$, data not shown). Further meticulous study regarding the vitamin $\mathrm{D}$ deficiency and osteoporosis is needed in the future.

We did not evaluate the relationships between wellknown risk factors, such as smoking and physical inactivity, and osteoporosis in this study. Among 110 subjects who provided information about smoking, only two subjects in this group were current/ex-smokers. The small proportion of subjects who were current/ex-smokers revealed no significant effect on osteoporosis. Because the level of physical activity was collected in a memory-recall questionnaire, it was difficult to obtain accurate data, particularly in the older age group.

Previous immigration studies showed that the duration of living in the migrated country was associated with BMD. Wang et al reported that Chinese women who had migrated and lived in Denmark for more than 12 years had a significantly higher BMD than those who had lived there for less than 12 years. ${ }^{8}$ Babbar $e t$ al also reported that Chinese women who had lived in New York for less than 10 years had a lower BMD than women who had lived in New York for more than 20 years. ${ }^{24}$ However, we did not observe a significant association between the duration of living in South Korea and osteoporosis. The median period of living 

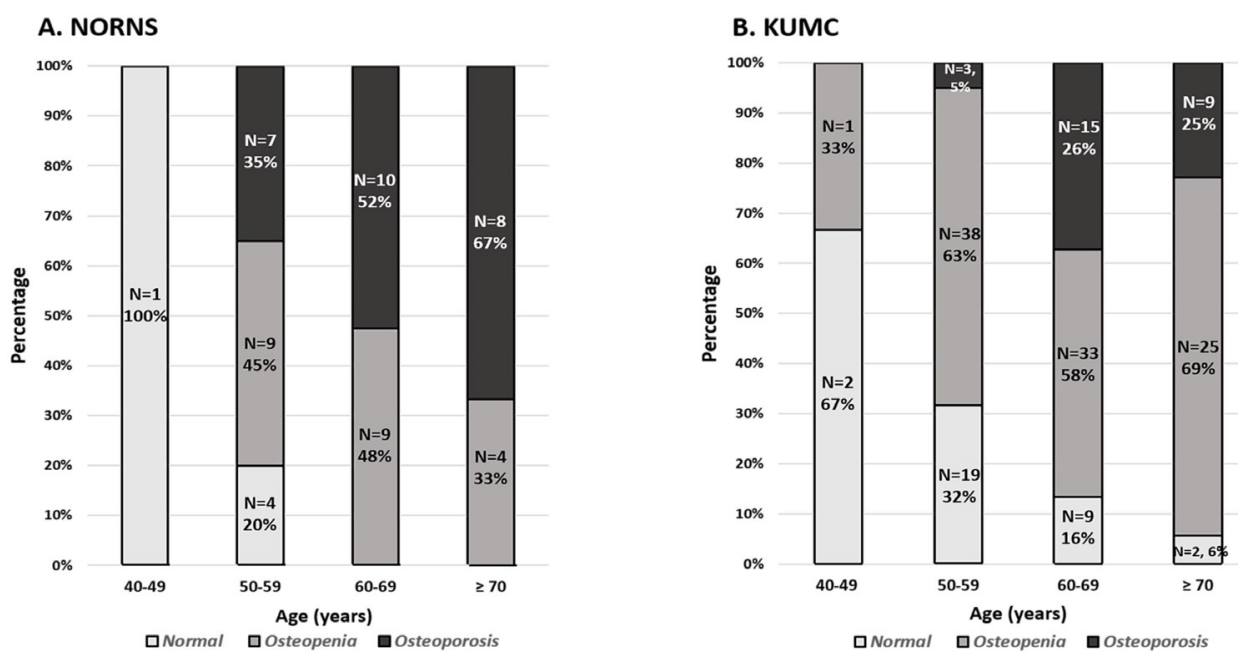

Figure 2 Proportion of subjects with osteoporosis, osteopenia and normal bone mineral density stratified by 10-year age groups in North Korean (A) and South Korean (B) postmenopausal women. NORNS, North Korean Refugee Health in South Korea; KUMC, Korea University Medical Center.

in South Korea in postmenopausal North Korean refugees (7.3 years; IQR 4.2-9.1 years) was relatively short compared with that in previous immigration studies, and less than $20 \%$ of postmenopausal North Korean refugees (10 of 52) had lived in South Korea for more than 10 years. Another explanation is that the duration of living in South Korea itself may not be a risk factor or indicator of acculturation, but may simply provide the circumstances in which other risk factors cause health problems. Our previous study based on the NORNS cohort identified that excess weight gain, but not duration of residence in South Korea, was an independent risk factor for metabolic syndrome, ${ }^{25}$ making our hypothesis more plausible.

None of the premenopausal North Korean refugees had a Z-score below the expected range for their age group; however, the median BMD at the lumbar spine was significantly lower than that of the South Korean premenopausal women. A previous study reported that young North Korean refugees aged 12-24 years had a significantly lower daily intake of energy and most nutrients, including protein and calcium, than that of general age-matched/sex-matched South Koreans. ${ }^{26}$ Our study also showed that premenopausal North Korean women

Table 4 Risk factors for osteoporosis in postmenopausal North Korean women identified by multivariate logistic regression analysis

\begin{tabular}{llll}
\hline Variables & OR & $\mathbf{9 5 \%} \mathbf{C l}$ & P value \\
\hline Age & 1.35 & 0.98 to 1.86 & 0.063 \\
Weight & 0.84 & 0.74 to 0.95 & 0.007 \\
Age at menarche & 1.45 & 0.96 to 2.19 & 0.077 \\
$\begin{array}{l}\text { Age at escape from North } \\
\text { Korea }\end{array}$ & 0.82 & 0.64 to 1.06 & 0.129 \\
\end{tabular}

Years living in South Korea $\quad 0.89 \quad 0.63$ to $1.25 \quad 0.489$

had significantly lower body weight and less physical activity than did South Korean premenopausal women. These results imply that young North Korean refugees are at high risk for osteoporosis, indicating the importance of scrupulous screening and follow-up.

It is worth noting that the prevalence of osteopenia in the postmenopausal KUMC group was high (62.2\%). A recent report from the Korean Society for Bone and Mineral Research demonstrated that the prevalence of osteopenia among women $>50$ years old was $48.9 \% .^{27}$ These results indicate that osteopenia is also not a minor problem in South Korean postmenopausal women.

Several limitations of this study need to be acknowledged. First, the relatively small number of participants may have reduced the power of the results and may not represent the entire population of female North Korean refugees living in South Korea. The NORNS study is
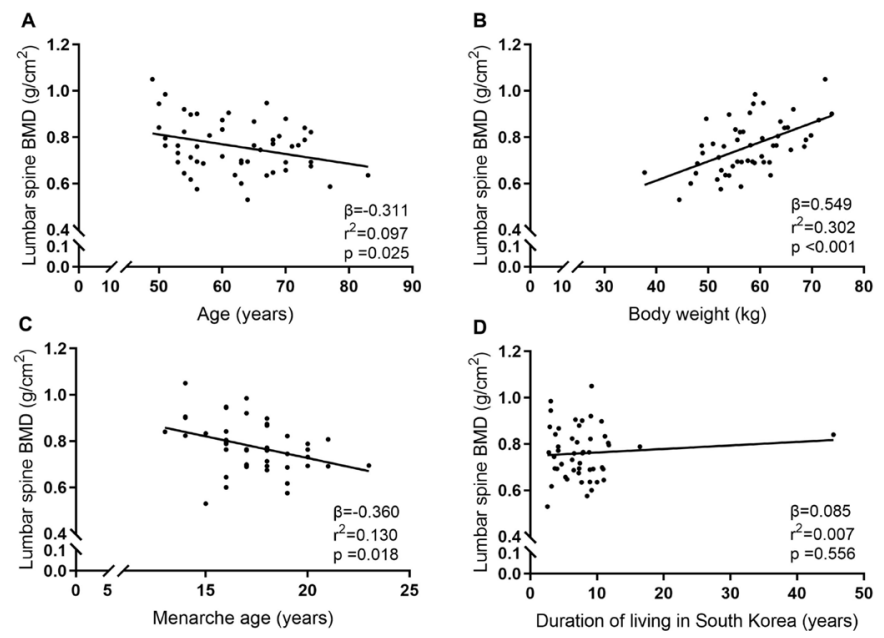

Figure 3 Simple linear regression between the lumbar spine bone mineral density (BMD) of postmenopausal North Korean women and age (A), body weight $(B)$, menarche age $(C)$ and duration of living in South Korea (D). 
based on the voluntary participation of North Korean refugees living in the Seoul metropolitan area, and it has taken considerable time to recruit large sample sizes. Second, we collected information about their postmenopausal status using self-reported questionnaires, which may have led to inaccuracy in the perimenopausal age group. Third, there is limited information regarding prior disease history that may affect the bone health of the KUMC control group.

\section{Conclusions}

This study reveals the high prevalence of osteoporosis in postmenopausal North Korean refugees living in South Korea compared with that in South Korean postmenopausal women. Outreach efforts are needed in this community to promote prevention, treatment and access to care, especially among those of older age, with low body weight, and in late menarche. Further longitudinal studies are needed to evaluate changes in bone health in this group.

Acknowledgements We especially thank the North Korean refugees who participated in the North Korea Refugee Health in South Korea (NORNS) study, as well as the medical doctors, nurses, and volunteers who contributed to the health examinations of these refugees.

Contributors SGK designed the NORNS study and supervised the data collection and data entry. JHA and KyeJK conducted the statistical analysis and drafted the manuscript. KyoJK, NamHK, and HYK coordinated the data collection. JHY, HJY, JAS, NanHK, KMC and SHB commented on and critically revised the manuscript. All authors read and approved the final manuscript.

Funding This study was partly supported by a grant of the Korean Health Technology R\&D Project (H14C2750), Ministry of Health \& Welfare, Republic of Korea.

Competing interests None declared.

Patient consent for publication Not required

Ethics approval This study was approved by the Institutional Review Board (IRB) of Korea University's Anam Hospital under IRB under process N0. ED08023.

Provenance and peer review Not commissioned; externally peer reviewed.

Data availability statement Data are available on reasonable request. The dataset generated during the current study is available on reasonable request from the corresponding author, SGK (k50367@korea.ac.kr).

Open access This is an open access article distributed in accordance with the Creative Commons Attribution Non Commercial (CC BY-NC 4.0) license, which permits others to distribute, remix, adapt, build upon this work non-commercially, and license their derivative works on different terms, provided the original work is properly cited, appropriate credit is given, any changes made indicated, and the use is non-commercial. See: http://creativecommons.org/licenses/by-nc/4.0/.

\section{ORCID iDs}

Kyung Mook Choi http://orcid.org/0000-0001-6175-0225

Sin Gon Kim http://orcid.org/0000-0002-7430-3675

\section{REFERENCES}

1 Center JR, Nguyen TV, Schneider D, et al. Mortality after all major types of osteoporotic fracture in men and women: an observational study. Lancet 1999;353:878-82.

2 Burge R, Dawson-Hughes B, Solomon DH, et al. Incidence and economic burden of osteoporosis-related fractures in the United States, 2005-2025. J Bone Miner Res 2007;22:465-75.
3 Johnell O, Kanis JA. An estimate of the worldwide prevalence and disability associated with osteoporotic fractures. Osteoporos Int 2006;17:1726-33.

4 Siris ES, Miller PD, Barrett-Connor E, et al. Identification and fracture outcomes of undiagnosed low bone mineral density in postmenopausal women: results from the National osteoporosis risk assessment. JAMA 2001;286:2815-22.

5 Kanis JA, Odén A, Johnell O, et al. The use of clinical risk factors enhances the performance of BMD in the prediction of hip and osteoporotic fractures in men and women. Osteoporos Int 2007; 18:1033-46.

6 Berg KM, Kunins HV, Jackson JL, et al. Association between alcohol consumption and both osteoporotic fracture and bone density. $\mathrm{Am} \mathrm{J}$ Med 2008;121:406-18.

7 Rizzoli R, Bischoff-Ferrari H, Dawson-Hughes B, et al. Nutrition and bone health in women after the menopause. Womens Health 2014;10:599-608.

8 Wang Q, Ravn P, Wang S, et al. Bone mineral density in immigrants from southern China to Denmark. A cross-sectional study. Eur J Endocrinol 1996;134:163-7.

9 Marquez MA, Melton LJ, Muhs JM, et al. Bone density in an immigrant population from Southeast Asia. Osteoporos Int 2001;12:595-604.

10 Park JJ, Park KB, Shafik N. Nuclear war and public health: rebalancing priorities and global health leadership. Lancet 2017;390:1733-4.

11 McCurry J. No end in sight for North Korea's malnutrition crisis. Lancet 2012;379:379-602.

12 Jeon W-T, Yu S-E, Cho Y-A, et al. Traumatic experiences and mental health of North Korean refugees in South Korea. Psychiatry Investig 2008;5:213-20.

$13 \mathrm{Kim}$ KJ, Kim YJ, Kim SH, et al. Vitamin D status and associated metabolic risk factors among North Korean refugees in South Korea: a cross-sectional study. BMJ Open 2015;5:e009140.

14 Holick MF. Vitamin D deficiency. N Engl J Med 2007;357:266-81.

15 Lee YH, Lee WJ, Kim YJ, et al. North Korean refugee health in South Korea (NORNS) study: study design and methods. BMC Public Health 2012;12:12-172.

16 von Elm E, Altman DG, Egger M, et al. The strengthening the reporting of observational studies in epidemiology (STROBE). STROBE.

17 World Health Organization. Assessment of fracture risk and its application to screening for postmenopausal osteoporosis: report of a WHO study group [meeting held in Rome from 22 to 25 June 1992]., 1994. Available: https://www.who.int/iris/handle/10665/ 39142

18 Spoorenberg T, Schwekendiek D. Demographic changes in North Korea: 1993-2008. Popul Dev Rev 2012;38:133-58.

19 Hansen MA, Overgaard K, Riis BJ, et al. Role of peak bone mass and bone loss in postmenopausal osteoporosis: 12 year study. BMJ 1991;303:961-4.

20 Rizzoli R, Bianchi ML, Garabédian M, et al. Maximizing bone mineral mass gain during growth for the prevention of fractures in the adolescents and the elderly. Bone 2010;46:294-305.

21 Hernandez CJ, Beaupré GS, Carter DR. A theoretical analysis of the relative influences of peak BMD, age-related bone loss and menopause on the development of osteoporosis. Osteoporos Int 2003;14:843-7.

22 Marcus E-L, Menczel J. Higher prevalence of osteoporosis among female holocaust survivors. Osteoporos Int 2007;18:1501-6.

23 Kin CFW, Shan WSY, Shun LJC, et al. Experience of famine and bone health in post-menopausal women. Int J Epidemiol 2007;36:1143-50.

24 Babbar RK, Handa AB, Lo C-man, et al. Bone health of immigrant Chinese women living in New York City. J Community Health 2006;31:7-23.

$25 \mathrm{Kim}$ YJ, Lee YH, Lee YJ, et al. Prevalence of metabolic syndrome and its related factors among North Korean refugees in South Korea: a cross-sectional study. BMJ Open 2016;6:e010849.

26 Choi SK, Park SM, Joung H. Still life with less: North Korean young adult defectors in South Korea show continued poor nutrition and physique. Nutr Res Pract 2010;4:136-41.

27 Korean Society for Bone and Mineral Research. Osteoporosis and osteoporotic fracture fact sheet, 2019. Available: http://www.ksbmr. org/bbs/?code=fact [Accessed 28 Nov 2019]. 